\title{
(2) OPEN ACCESS \\ Knowledge and practice of home blood pressure monitoring 6 months after the risk and assessment management programme: does health literacy matter?
}

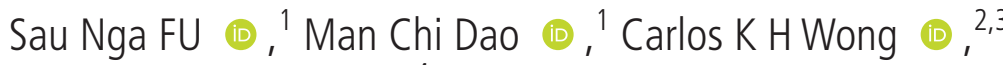 \\ Bernard M Y Cheung (i) ${ }^{4}$
}

- Additional online supplemental material is published online only. To view, please visit the journal online (http://dx.doi.org/10.1136/ postgradmedj-2020-139329).

${ }^{1}$ Department of Family Medicine and Primary Health Care, Hospital Authority Kowloon West Cluster, New Territories, Hong Kong

${ }^{2}$ Department of Family Medicine and Primary Care, Li Ka Shing Faculty of Medicine, University of Hong Kong, Hong Kong SAR, China

${ }^{3}$ Department of Pharmacology and Pharmacy, Li Ka Shing Faculty of Medicine, University of Hong Kong, Hong Kong SAR, China

${ }^{4}$ Department of Medicine, Li Ka Shing Faculty of Medicine, University of Hong Kong, Hong Kong SAR, China

Correspondence to Dr Sau Nga FU, Family Medicine \& Primary Health Care, Hospital Authority Kowloon West Cluster, N.T., Hong Kong; fsn299@ha.org.hk

Received 5 November 2020 Revised 8 April 2021 Accepted 21 April 2021
Check for updates

(c) Author(s) (or their employer(s)) 2021. Re-use permitted under CC BY-NC. No commercial re-use. See rights and permissions. Published by BMJ.

To cite: FU SN, Dao MC, Wong $\mathrm{CKH}$, et al. Postgrad Med J Epub ahead of print: [please include Day Month Year]. doi:10.1136/ postgradmedj-2020-139329
ABSTRACT

Background Little is known whether patients with lower health literacy could retain the practice and knowledge of home blood pressure monitoring (HBPM) after an educational programme.

Methods A cluster randomised controlled trial in five primary care clinics recruited participants with uncontrolled hypertension. Clinics were randomised either to a HBPM group education (Risk Assessment and Management Programme (RAMP-group), or individual counselling of self-management (RAMP-individual). Health literacy was assessed by the Chinese Health Literacy Scale for Chronic Care. Practice and knowledge of HBPM were surveyed by a 10-item HBPM knowledge checklist and patient record review 6 months after interventions. Predictors for regular HBPM and good HBPM knowledge were assessed by multivariate logistic regression models.

Results 287 participants (RAMP-group: 151; RAMPindividual: 136) were follow-up for 6 months. 272 participants completed the knowledge questionnaires (response rate $94.8 \%$ ). 67.8\% of the participants performed HBPM regularly, and there was no statistical difference between both interventions. Age more than 65 (adjusted odds ratios (aOR) $2.58,95 \% \mathrm{Cl} 1.37$ to $4.86, p=0.003$ ), not working (aOR $2.34,95 \% \mathrm{Cl} 1.10$ to 4.97, $\mathrm{p}=0.027$ ) and adequate health literacy (aOR 2.25, $95 \% \mathrm{Cl} 1.28$ to $3.95, \mathrm{p}=0.005$ ) predicted regular HBPM Participants in RAMP-group demonstrated a significant lower body weight than those in RAMP-individual $(-0.3 \pm 2.0 \mathrm{~kg} v \mathrm{~s}+0.7 \pm 1.7 \mathrm{~kg}, \mathrm{p}<0.001)$. The RAMPgroup participants were eight times more likely to have full HBPM knowledge score than the RAMP-individual participants (aOR 8.46, 95\% Cl 4.68 to $15.28, p<0.001$ ). Conclusion Patients could retain HBPM knowledge better after RAMP-group than RAMP-individual. Older, retired and patients with adequate health literacy were more likely to continue weekly HBPM 6 months after education.

Trial registration number NCT02551393.

\section{BACKGROUND}

Several national and international guidelines recommended home blood pressure monitoring (HBPM) in the management of hypertension (HT), particularly for those with suspected discrepancies of blood pressure (BP) reading in office and other casual situations. ${ }^{12}$ Despite the worldwide unsatisfactory BP control in different populations, only around half of the patients with HT perform HBPM regularly. ${ }^{34}$ Different meta-analysis studies demonstrated a reduction in patients' BP after interventions to facilitate HBPM. ${ }^{5}{ }^{6}$ However, HBPM has potential pitfalls in itself, namely inaccurate HBPM devices, ${ }^{7}$ the need for coaching on proper HBPM techniques, ${ }^{8}$ selectively or erroneously report BP values by patients, ${ }^{9}$ and the cost of equipment and maintenance. These may hinder patients from using HBPM. ${ }^{10}$ Therefore, some of the clinicians were hesitated to promote HBPM in their practice. ${ }^{11} 12$

High-quality HBPM could be achieved by education intervention and increasing patient-clinician contact time. ${ }^{13}$ Given the multiple potential sources of inaccuracy in HBPM measurement, ${ }^{14}$ the sustainability of high-quality HBPM after an educational intervention may be questionable. Knowledge of HBPM and practice of regular HBPM may be affected by patients' age, sex, educational level and health literacy (HL). ${ }^{13}$

This study performed an interim patient outcome assessment of a cluster randomised controlled trial. The study aims to compare whether patients can retain HBPM knowledge and regular HBPM practice 6 months after two types of multidisciplinary education programmes. The sociodemographic predictors for desirable HBPM outcomes were also assessed.

We hypothesise that more patients who attended group education could retain better HBPM knowledge and regular HBPM than those attended conventional individual counselling 6 months postinterventions. Patients with better HL or higher educational level would have higher compliance with regular HBPM and better HBPM knowledge.

\section{METHOD}

Written informed consents were obtained before the patients participated in the study.

\section{Study design}

This study is an interim outcome analysis of a cluster randomised controlled trial in five government primary care clinics. The methodology and sample size calculation was reported elsewhere. ${ }^{15}$ We included clinics with more than three family physicians, and their number of registered 
hypertensive patients is more than 6000 in the past 12 months. Three clinics were allocated to the intervention groups, while two clinics were assigned to the control group by simple randomisation. Patients were recruited if they have uncontrolled HT. Uncontrolled HT was defined as clinic SBP more than $140 \mathrm{mmHg}$ (for those aged <80), more than $150 \mathrm{~mm} \mathrm{Hg}$ (for those aged $\geq 80$ ) or DBP more than $90 \mathrm{~mm} \mathrm{Hg}$ in their most recent two clinic visits. Higher cut-off for uncontrolled HT was adopted for older adults (age $\geq 80$ ) according to the recommendation of treatment initiation in the Eighth Joint National Committee guideline and the National Institute for Health and Clinical Excellence 2014 guideline. $^{12}$

\section{Control clusters (Risk Assessment and Management Programme-individual, usual care)}

According to study clinics' HT management protocol, all patients with uncontrolled HT are invited to the Risk Assessment and Management Programme (RAMP) annually. ${ }^{3}$ RAMP consists of an individual $15 \mathrm{~min}$ face to face nurse clinic. Clinic nurses provide patients' clinical parameters results, assess patients' overall cardiovascular disease (CVD) risk, counsel on lifestyle modification and refer patients to appropriate allied health services such as physiotherapy, dietitian or occupational therapist. Patients already on HBPM are advised to bring their own HBPM devices for checking machine functions and patients' HBPM technique.

\section{Intervention clusters (RAMP-group)}

Patients and their family members were invited to the group educational sessions after the first RAMP nurse clinic. The RAMP-group for 10-15 participants lasted for 2 hours offered the day group (9:00-17:00 hours) or the evening group (18:00-22:00 hours). Every participant received an automatic branchial type HBPM device and a self-administered BP record booklet. ${ }^{16}{ }^{17}$ Second author MD, who is a family doctor, gave a 30 min seminar about basic knowledge of HT, antihypertensive drugs, CVD risk factors and understanding of home BP and office $\mathrm{BP}^{18}$ The participants then watched a 10 min video introducing HBPM procedures. Our clinic nurses then demonstrate how to use the HBPM devices, and all participants practised on their device. Lastly, all participants were divided into groups of 3-4 to practise HBPM with their facilitators, might be doctors, nurses or clinic assistances. The facilitators went through a 10 items checklist of HBPM procedures until the participants got all items correct. ${ }^{19}$

Six weeks later, all participants returned their BP devices and attended an individual face-to-face nurse follow-up. Their healthy lifestyle, drug compliance and HBPM practice were reviewed. They were encouraged to buy their own validated HBPM devices and communicate their HBPM records with clinicians.

\section{Baseline assessment}

Clinic nurses identified patients with uncontrolled HT They then asked for their written consents of this study. Trained research assistants then assessed participants' sociodemographic data, HT drug prescription and HL by the Chinese Health Literacy Scale for Chronic Care (CHLSCC). All biochemical markers were retrieved from the computerised patient records. Biochemical outcomes included body weight, fasting blood sugar and lowdensity lipoprotein (LDL).

\section{Table 1 10-item HBPM knowledge checklist}

\begin{tabular}{|c|c|c|c|c|}
\hline No & & BHS & AHS & RACGP \\
\hline 1. & $\begin{array}{l}\text { What should be avoided before taking } \\
\text { measurements at least } 30 \text { min before measurement? } \\
\text { Answer: Do not exercise, smoke or consume foods or } \\
\text { drinks containing caffeine (such as tea or coffee) }\end{array}$ & $\checkmark$ & $\checkmark$ & $\checkmark$ \\
\hline 2. & $\begin{array}{l}\text { How long should you rest and relax without any } \\
\text { distractions } \\
\text { Answer: at least } 5 \text { min (time between } 5 \text { min and } 30 \\
\text { min is acceptable) }\end{array}$ & $\checkmark$ & $\checkmark$ & $\checkmark$ \\
\hline
\end{tabular}

3. What is the dressing requirement during measurement? Answer: Wear loose-fitting and comfortable clothes, Roll up the sleeve to expose your upper arm and wrap the cuff around it.

4. What are the appropriate characteristics of table and $\checkmark \quad \checkmark \quad \checkmark$ chair used for HBPM?

Answer: Choose a stable table and chair of appropriate height (at heart level) with armrest. How should your back and feet be placed? Answer: Sit comfortably and relaxed with your back supported, keep your feet on the floor and do not cross the legs

5. Show me your HBPM cuff (Check if the cuff size is appropriate)

6. Could you show me how you put on your cuff? (Observe: Place cuff in an appropriate position: The lower border of the cuff should be $2 \mathrm{~cm}$ above the pit of elbow, which is approximately two fingerbreadths. Make sure the tubing is placed at the centre of your arm facing the front and that the sensor is correctly placed.)

7. Check cuff with appropriate tightness: Pull the end of the cuff so that it is wrapped evenly and firmly around your arm. Check that the tightness of the cuff is proper: you should be able to just slip two fingertips beneath the cuff, near its edge at the top end

8. Please start to measure now (Observe: Press start button, relax during measurement (no talking/movement)

9. How many times do you measure? When? Answer: Repeat measurement at least 1 min after complete release of the cuff

10 Can you write down the readings on this booklet? Record all readings appropriately

Total score (full mark 10)

AHS, American Heart Association ${ }^{20}$; BHS, British Hypertension Society ${ }^{21}$; BP, blood pressure; HBPM, home blood pressure monitoring; RACGP, Royal Australian College of General Practitioner22.

\section{Outcomes assessment}

Apart from repeating baseline biochemical assessment at 6 months after intake, clinic nurses also asked the 10 items HBPM knowledge questionnaire and the practice of HBPM. HBPM practice was verified by doctors' and nurses' consultation records.

Chinese Health Literacy Scale for Chronic Care

The CHLSCC is a locally validated tool to assess HL among Chinese patients with chronic illness. It displayed a good internal reliability (Cronbach's $\alpha=0.91) .^{6}$ It assesses remembering, understanding, applying and analysing ability. Participants scored 36 out of 48 or above indicated adequate HL; otherwise, they had inadequate HL.

\section{0-item HBPM knowledge checklist}

Table 1 shows the 10-item HBPM knowledge questionnaire. It was developed according to the American Heart 
Table 2 Patient's sociodemographic and clinical parameters at baseline

\begin{tabular}{|c|c|c|c|c|}
\hline Characteristics & RAMP-individual (N=137) & RAMP-Group (N=152) & Total $(\mathrm{N}=289)$ & P value* \\
\hline Age (year; mean $\pm S D$, median) & $67.9 \pm 10.2,67$ & $66.1 \pm 9.7,65$ & $67.0 \pm 9.9,66$ & 0.528 \\
\hline \multicolumn{5}{|l|}{ Gender (\%) } \\
\hline - Male & $58(42.3 \%)$ & $55(36.2 \%)$ & $113(39.1 \%)$ & 0.285 \\
\hline - Female & $79(57.7 \%)$ & $97(63.8 \%)$ & $176(60.9 \%)$ & \\
\hline \multicolumn{5}{|l|}{ Education (\%) } \\
\hline - Primary or below & $81(59.1 \%)$ & $97(63.8 \%)$ & $178(61.6 \%)$ & 0.352 \\
\hline - Secondary school & $48(35.0 \%)$ & $51(33.6 \%)$ & $99(34.3 \%)$ & \\
\hline - University or above or unknown & $8(5.8 \%)$ & $4(2.6 \%)$ & $12(4.2 \%)$ & \\
\hline \multicolumn{5}{|l|}{ Occupation (\%) } \\
\hline - Not employed/housewife & $105(76.6 \%)$ & $120(78.9 \%)$ & $225(77.9 \%)$ & 0.637 \\
\hline - Working & $32(23.4 \%)$ & $32(21.1 \%)$ & $64(22.1 \%)$ & \\
\hline \multicolumn{5}{|l|}{ CHLSCC } \\
\hline - Total 0-48: mean \pm SD, median & $28.11 \pm 13.73,30.5$ & $35.00 \pm 12.76,39.0$ & $31.70 \pm 13.65,35$ & $<0.001 \dagger$ \\
\hline - Adequate $(\geq 36)(\%)$ & $51(37.2 \%)$ & $94(61.8 \%)$ & $145(50.2 \%)$ & $<0.001 \dagger$ \\
\hline - Inadequate $(<36)(\%)$ & $86(62.8 \%)$ & $58(38.2 \%)$ & $144(49.8 \%)$ & \\
\hline \multicolumn{5}{|l|}{ Smoking status } \\
\hline Non-smoker & $92(67.2 \%)$ & $121(79.6 \%)$ & $213(73.7 \%)$ & 0.056 \\
\hline Current smoker & $7(5.1 \%)$ & $5(3.3 \%)$ & $12(4.2 \%)$ & \\
\hline - Ex-smoker & $38(27.7 \%)$ & $26(17.1 \%)$ & $64(22.1 \%)$ & \\
\hline \multicolumn{5}{|l|}{ Clinic BP } \\
\hline - Systolic BP (mm Hg, mean \pm SD) & $152 \pm 9.81$ & $152.0 \pm 10.4$ & $152.1 \pm 10.1$ & 0.775 \\
\hline - Diastolic BP (mm Hg, mean \pm SD) & $78.4 \pm 10.6$ & $80.76 \pm 11.9$ & $79.7 \pm 11.4$ & 0.087 \\
\hline $\mathrm{BMI}\left(\mathrm{kg} / \mathrm{m}^{2} ;\right.$ mean $\left.\pm \mathrm{SD}\right)$ & $26.49 \pm 4.31$ & $26.31 \pm 4.28$ & $26.39 \pm 4.27$ & 0.774 \\
\hline - Underweight $(<18.5)$ & $4(2.9 \%)$ & $3(2.0 \%)$ & $7(2.4 \%)$ & 0.937 \\
\hline - Normal $(\geq 18.50-<23)$ & $22(16.1 \%)$ & $24(15.8 \%)$ & $46(15.9 \%)$ & \\
\hline - Overweight $(\geq 23-<25)$ & $28(20.4 \%)$ & $29(19.1 \%)$ & $57(19.7 \%)$ & \\
\hline - Obese $(\geq 25)$ & $83(60.6 \%)$ & $96(63.2 \%)$ & $179(61.9 \%)$ & \\
\hline $\begin{array}{l}\text { Duration of hypertension since diagnosis } \\
\text { (years } \pm S D \text { ) }\end{array}$ & $10.92 \pm 9.32$ & $8.43 \pm 8.04$ & $9.62 \pm 8.75$ & $0.015 \dagger$ \\
\hline Uncomplicated hypertension (\%) & $81(59.1 \%)$ & $103(67.8 \%)$ & $184(63.7 \%)$ & 0.127 \\
\hline Complicated hypertension (\%) & $56(40.9 \%)$ & $49(32.2 \%)$ & $105(36.3 \%)$ & \\
\hline
\end{tabular}

${ }^{*} \mathrm{P}$ value of proportions by Pearson $\chi^{2}$ tests; continuous variables by Student's t-tests.

$+P$ value $<0.05$ are bold

BMI, body mass index; BP, blood pressure; CHLSCC, Chinese Health Literacy Scale for Chronic Care; RAMP, Risk Assessment and Management Programme.

Association recommendations, ${ }^{20}$ the British Hypertension Society $^{21}$ and Royal Australian College of General Practitioners patient education material. ${ }^{22}$ The first to third items are about preparing themselves, including clothing, rest and avoidance of stimulants before measurement. The fourth to the seventh item is about body positioning and cuff application. The eighth to ninth items is about the frequency of HBPM measurement. The last item is about correct HBPM reading recording. The results are presented as scoring over 10 (full mark). The checklist is administered by face-to-face interview, supplemented by patient's consultation records and telephone interview if patients could not be contacted 6 months later.

\section{HBPM practice questionnaire}

Participants reported if they practised HBPM regularly (Yes/No), if they owned their HBPM devices (yes/no), how frequent they measured their BP (daily, weekly, monthly, less than monthly), how many times they measured in a day (once, twice, three times, four times or more). Their answers were verified by authors via the patients' consultation record. HBPM practice was routinely documented by doctors and nurses during patients' quarterly follow-up.
Participants were defined as performing HBPM regularly if they measured more than once weekly.

\section{Statistical analysis}

The participants' descriptive statistics were reported as means and SD, or frequencies and percentages as appropriate. This study endpoint was 6 months after the interventions. The primary outcome was the differences in the proportion between participants attained RAMP-individual and RAMP-group having good HBPM knowledge using $\chi^{2}$ tests. The secondary outcomes included the differences in the proportion between the participants attained RAMPindividual and RAMP-group measuring home BP regularly using $\chi^{2}$ tests. Subgroup analysis of the participants' outcomes with adequate and inadequate HL was performed because of their baseline difference. The unadjusted OR (aOR) was calculated for the predictors for regular HBPM and for having good HBPM knowledge. The aOR was calculated from the multivariant logistic regression model. The ORs were adjusted by age, sex, educational level, HL level, occupation and whether the participant attended RAMPgroup or RAMP-individual. A $\mathrm{p}<0.05$ was considered as 


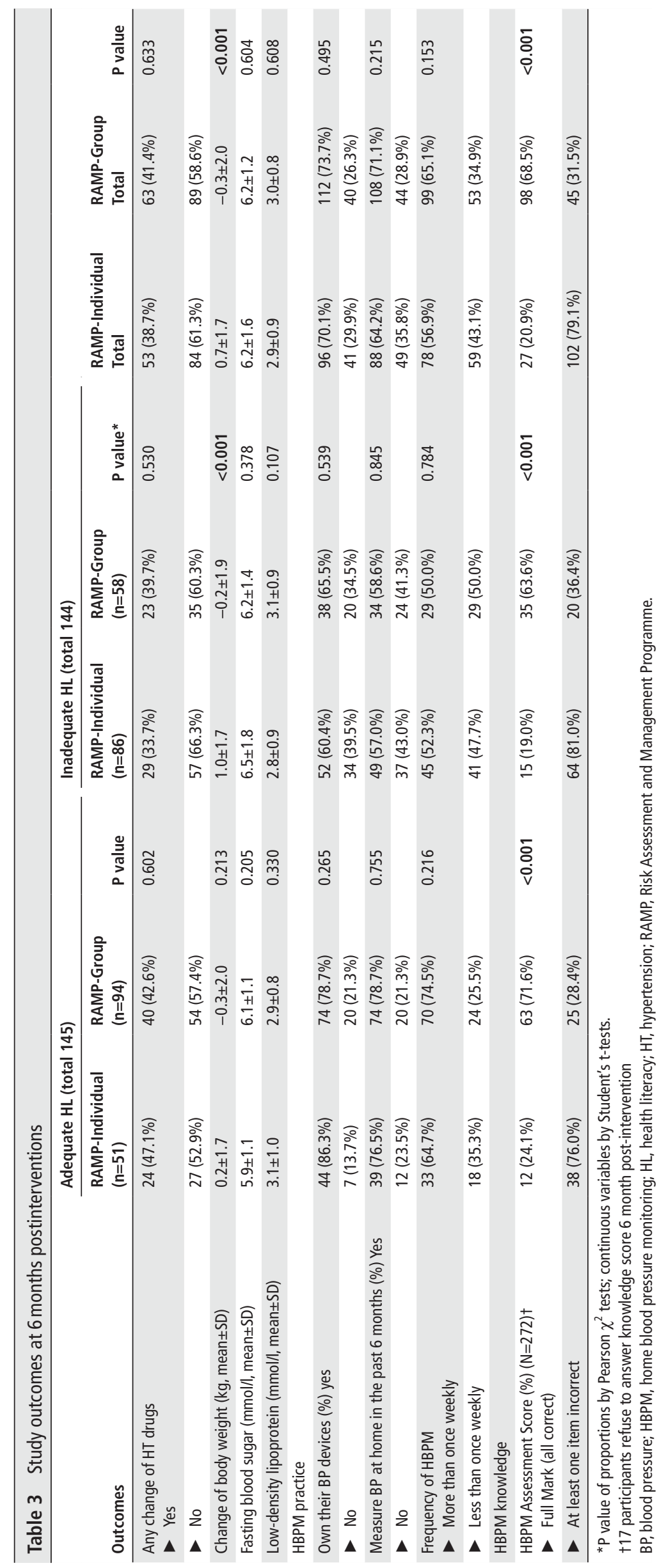


significant. All analyses were performed using SPSS V.25 (IBM).

\section{RESULTS}

A total of 289 participants were recruited and follow-up until 6 months. Two participants from the RAMP-individual passed away before study endpoint, therefore, excluded from the analysis. A total of 272 participants completed the 6 months questionnaires (response rate of 94.8\%) except 17 of them refused to answer the HBPM knowledge score. Online supplemental table $\mathrm{S}$ showed the details of missing data. Table 2 shows the participants' characteristics. Their mean age was 67.0 (SD 9.9); almost two-thirds were women. Their educational level was low. Around $60 \%$ of them attended primary school, and another one-third of them attended secondary school. There were significantly more participants with adequate HL in RAMP-group than those in RAMP-individual. Their baseline clinic BP, body weight, waist circumference, proportions of complicated HT and drug compliance were similar.

Table 3 demonstrates the participants' outcomes at 6 months postintervention. Due to the baseline difference in HL, subgroup analysis of participants with adequate and inadequate HL were performed. Among the participants with adequate HL, there was statistically insignificant difference in change of body weight (BW)after intervention. However, among the participants with inadequate HL, the RAMP-group had mean weight loss $(-0.2 \pm 1.9 \mathrm{~kg})$, when compared with the RAMP-individual had mean weight gain $(+1.0 \pm 1.7 \mathrm{~kg})$. Overall, the RAMP-group had statistically more favourable weight change than the RAMP-individual. There was no statistically significant difference in the change in HT drugs, fasting blood sugar level and LDL level.

Most of the participants from the RAMP-group (68.5\%) could score full marks in the knowledge score questionnaire, while only $20.9 \%$ of the participants from the RAMPindividual could achieve the same score $(\mathrm{p}<0.001)$. More than $60 \%$ of participants with both adequate and inadequate HL could score full marks in RAMP-group. Only around $20 \%$ of the RAMP-individual scored full mark no matter they had adequate or inadequate HL.

Concerning about HBPM practice, there was no difference in proportions of participants in possession of HBPM device, regular measurement of HBPM and measuring at least once weekly between RAMP-group and RAMPindividual. There were more than two-thirds of participants owned their HBPM devices. $71.1 \%$ of the RAMP-group participants continued to measure HBPM more than once weekly. The proportions were the highest among the RAMPgroup with adequate HL (78.7\%) compared with the lowest in the RAMP-individual with inadequate HL (57.0\%).

The predictors for regular HBPM and good HBPM knowledge were illustrated in table 4 using binary logistic regression models. In the multivariate model, patients older than 65 (adjusted odds ratio (aOR) 2.58, 95\% CI 1.37 to 4.86, $\mathrm{p}=0.003)$, who were not working (aOR $2.34,95 \% \mathrm{CI}$ 1.10 to $4.97, \mathrm{p}=0.027$ ) and with adequate $\mathrm{HL}(\mathrm{aOR} 2.25$, $95 \%$ CI 1.28 to $3.95, \mathrm{p}=0.005$ ) predicted regular HBPM. The only predictor for getting full-score in HBPM knowledge was attended RAMP-group instead of RAMP-individual $(\mathrm{aOR}=8.46,95 \% \mathrm{CI} 4.68$ to $15.28, \mathrm{p}<0.001)$. Age, sex, educational level, HL, HT duration, and being obese did not predict good HBPM knowledge.

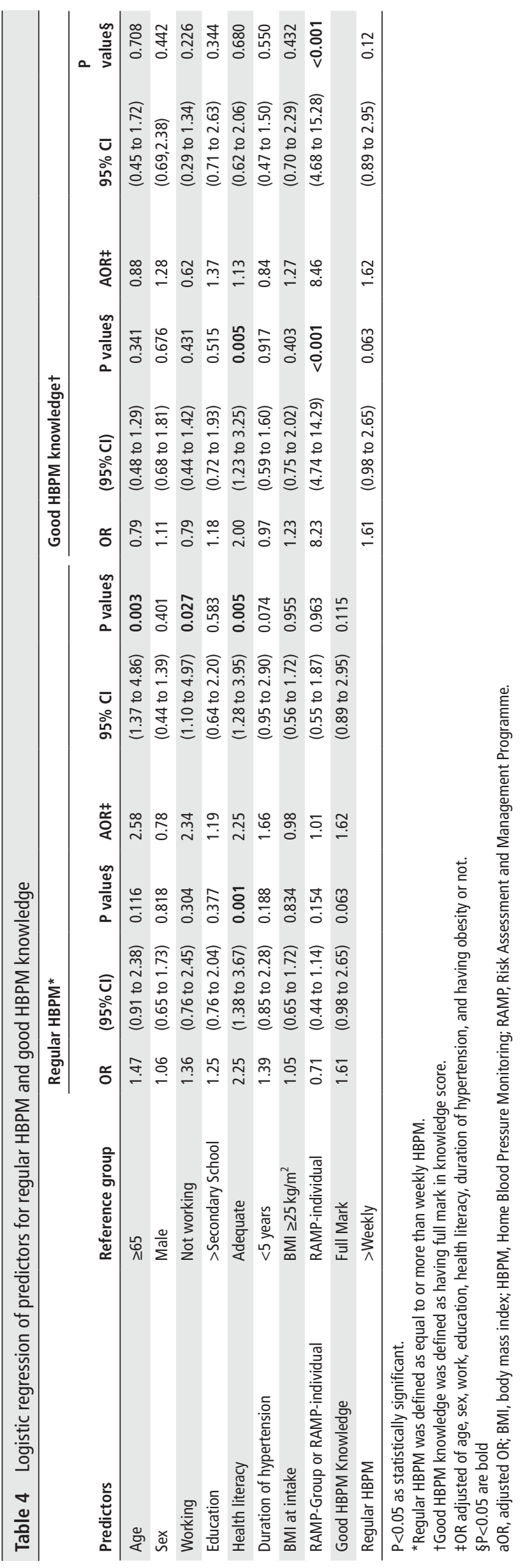




\section{DISCUSSION}

After two different educational interventions: group education focusing on HBPM and individual counselling on HT self-management, more than $70 \%$ of the participants owned their HBPM devices. Two-thirds performed HBPM at least once weekly. The high acceptance of HBPM after interventions was probably related to clinicians' promotion and demonstrated of HBPM. ${ }^{23}$ The RAMP-group scored significantly more full-mark in the HBPM knowledge checklist. Similar to previous studies, the finding supports groupintervention focused on HBPM knowledge and technique. ${ }^{8} 19$ The reason for better HBPM knowledge could be explained by interactive group education with information delivery, HBPM procedure demonstration and hands-on practice could improve and retain essential knowledge in HBPM. The professional-patient contact time was shortened in this study (total 3 hours) than previous successful intervention in USA (total 12 hours). ${ }^{18}$ Less contact time implied less healthcare cost, especially to the population with lower educational level or HL.

Promotion of regular HBPM practice is achievable by both interventions. The study findings further support interventions to increase in knowledge of treatment and complications of HT, the use of HBPM readings and the proper technique of HBPM. ${ }^{24} 25$

There were multiple potential sources of HBPM measurement difficulties. ${ }^{14}$ Therefore, many patients, particularly those from lower socioeconomic classes, may experience more barriers to perform HBPM regularly and correctly. ${ }^{26} 27$ This study found patients were less likely to have regular HBPM if they were younger, working or with inadequate HL. In Ayala et al and Seidlerová et al have also found older age group and people with adequate HL were more likely to perform HBPM regularly. ${ }^{3} 28$ Interventions focusing on attitude, knowledge and technique of HBPM could further improve their HBPM knowledge compared with conventional counselling on overall HT self-management. The RAMPgroup patients could share higher-quality HBPM reading to their clinicians, to design their daily HT management plan. The proven high knowledge in HBPM after focused education could encourage clinicians to trust patients' HBPM findings and promote HBPM in their practice. ${ }^{11} 12$

This study's strength includes that it is a pragmatic result from a primary care cluster-randomised controlled trial. The response rate to follow-up 6 months postintervention was satisfactory. The HBPM knowledge score was developed according to international recommendations to patients. We have performed subgroup analysis which mainly looks into the difference in outcomes between patients with adequate and inadequate HL.

This study's limitation includes the practice of HBPM could only be verified by patients' reported habit with their consultation records. Although this method is widely accepted in a bigger population survey, there is a possibility of observer and recall bias. ${ }^{8914}$ Nowadays, there were HBPM devices with electronically linked up with patients' mobile devices, or even healthcare professional's computer system so that the immediate HBPM records could be accurately achieved. In this study, the research subjects were mostly from a lower socioeconomic class, and they could not afford the more advanced HBPM models.

In conclusion, HL or educational level were not limiting factors to acquire HBPM knowledge. Patients could retain
Main messages

- Current research questions are: more patients who attended group education could retain better HBPM knowledge and regular HBPM than those attended conventional individual counselling 6 months post-interventions.

- Patients with better HL or higher educational level would have higher compliance with regular HBPM and better HBPM knowledge.

- In this study, more than $70 \%$ of participants continued HBPM 6 months after both types of interventions.

- Patients age more than 65, not working and with adequate health literacy were more likely to perform at least weekly HBPM.

\section{What is already known on the subject}

- Regular home blood pressure monitoring (HBPM) with additional education and feedback intervention was known to reduce blood pressure of patients with hypertension.

- High-quality HBPM could possibly be achieved in patients with low health literary or educational level.

HBPM knowledge better possessed after focused group education than individual counselling on general HT management. Older, retired and patients with adequate HL were more likely to continue weekly HBPM 6 months after education. Healthcare professionals can focus continuous educational intervention for those younger, working-class and those with inadequate HL for regular HBPM.

\section{Twitter Carlos K H Wong @CarlosWongHKU}

Acknowledgements Ethical approval was obtained from the Research Ethics Committee of the Kowloon West Cluster, Hospital Authority of Hong Kong.

Contributors SNF, MCD, CKHW and BMYC designed the study. SNF and MCD collected the data. SNF, MCD and CKHW conducted the statistical analysis. SNF, MCD, CKHW and BMYC analyzed and interpreted the data. SNF, MCD, CKHW and BMYC wrote the manuscript. All authors critically reviewed and approved the final version of the manuscript.

Funding The authors have not declared a specific grant for this research from any funding agency in the public, commercial or not-for-profit sectors.

\section{Competing interests None declared.}

\section{Patient consent for publication Not required.}

Ethics approval This study was approved by the Hong Kong Hospital Authority, Kowloon West Cluster Clinical Research Ethics Committee, reference number: KW/ EX-15-115(88-14).

Provenance and peer review Not commissioned; externally peer reviewed.

Data availability statement Data are available in a public, open access repository. All data relevant to the study are included in the article or uploaded as online supplemental information. All data in this study are deidentified.

Open access This is an open access article distributed in accordance with the Creative Commons Attribution Non Commercial (CC BY-NC 4.0) license, which permits others to distribute, remix, adapt, build upon this work non-commercially, and license their derivative works on different terms, provided the original work is properly cited, appropriate credit is given, any changes made indicated, and the use is non-commercial. See: http://creativecommons.org/licenses/by-nc/4.0/.

\section{ORCID iDs}

Sau Nga FU http://orcid.org/0000-0002-6491-654X

Man Chi Dao http://orcid.org/0000-0002-8793-7167 
Carlos K H Wong http://orcid.org/0000-0002-6895-6071

Bernard M Y Cheung http://orcid.org/0000-0001-9106-7363

\section{REFERENCES}

1 Whelton PK, Carey RM, Aronow WS, et al. 2017 ACC/AHA/AAPA/ABC/ACPM/ AGS/APhA/ASH/ASPC/NMA/PCNA guideline for the prevention, detection, evaluation, and management of high blood pressure in adults. J Am Coll Cardiol 2018;71:e127-248.

2 McCormack T, Krause T, O'Flynn N. Management of hypertension in adults in primary care: NICE guideline. Br J Gen Pract 2012;62:163-4.

3 Ayala $C$, Tong $X$, Neeley $E$, et al. Home blood pressure monitoring among adultsAmerican heart association cardiovascular health consumer survey, 2012. J Clin Hypertens 2017;19:584-91.

4 Wang Y, Wang Y, Gu H, et al. Use of home blood pressure monitoring among hypertensive adults in primary care: Minhang community survey. Blood Press Monit 2014:19:140-4.

5 Glynn LG, Murphy AW, Smith SM, et al. Self-Monitoring and other nonpharmacological interventions to improve the management of hypertension in primary care: a systematic review. Br J Gen Pract 2010;60:e476-88.

6 Tucker KL, Sheppard JP, Stevens R, et al. Self-Monitoring of blood pressure in hypertension: a systematic review and individual patient data meta-analysis. PLoS Med 2017; 14:1549-1277.

7 Ringrose JS, Polley G, McLean D, et al. An assessment of the accuracy of home blood pressure monitors when used in device owners. Am J Hypertens 2017;30:683-9.

8 Mondal S, Mondal H, Dutta R, et al. Competency in home blood pressure monitoring and effect of training program on competency. Journal Of Clinical And Diagnostic Research 2018;12:0C10-14.

9 Sendra-Lillo J, Martínez-Martínez F, García-Corpas JP, et al. Validity of home blood pressure measurements manually registered by patients after an educational session provided by community pharmacists. Blood Press Monit 2015;20:232-6.

10 Hwang KO, Thomas EJ, Petersen LA. Use of home blood pressure results for assessing the quality of care for hypertension. JAMA 2018;320:1753-4.

11 Tirabassi J, Fang J, Ayala C. Attitudes of primary care providers and recommendations of home blood pressure monitoring--DocStyles, 2010. J Clin Hypertens 2013;15:224-9.

12 Dugelay G, Kivits J, Desse L, et al. Implementation of home blood pressure monitoring among French GPs: a long and winding road. PLoS One 2019;14:e0220460.

13 Fu SN, Dao MC, Wong CKH, et al. The association of health literacy with high-quality home blood pressure monitoring for hypertensive patients in outpatient settings. Int $\mathrm{J}$ Hypertens 2020;2020:7502468.
14 Kallioinen N, Hill A, Horswill MS, et al. Sources of inaccuracy in the measurement of adult patients' resting blood pressure in clinical settings: a systematic review. J Hypertens 2017;35:421-41.

15 SN F, Dao MC, Luk W. A cluster-randomized study on the risk assessment and management program for home blood pressure monitoring in an older population with inadequate health literacy. J Clin Hypertens 2020;22:1565-76.

16 Leblanc M-E, Cloutier L, Veiga EV. Knowledge and practice outcomes after home blood pressure measurement education programs. Blood Press Monit 2011;16:265-9.

17 Dawes MG, Kaczorowski J, Swanson G, et al. The effect of a patient education booklet and $\mathrm{BP}$ 'tracker' on knowledge about hypertension. A randomized controlled trial. Fam Pract 2010;27:472-8.

18 Kim KB, Han H-R, Huh B, et al. The effect of a community-based self-help multimodal behavioral intervention in Korean American seniors with high blood pressure. Am J Hypertens 2014;27:1199-208

19 Dymek J, Skowron A, Polak W, et al. Assessment of knowledge and skills of patients with hypertension related to self-measurement of blood pressure (SBPM). Arterial Hypertension 2015;19:39-44.

20 Shimbo D, Artinian NT, Basile JN, et al. Self-Measured blood pressure monitoring at home: a joint policy statement from the American heart association and American Medical association. Circulation 2020;142:e42-63.

21 British Hypertension Society. Taking your blood pressure at home, 2020. Available: https://bihsoc.org/wp-content/uploads/2017/09/How_to_instructional_leaflet.pdf [Accessed 23 Sep 2020].

22 Sharman JE, Howes F, Head GA, et al. How to measure home blood pressure: recommendations for healthcare professionals and patients. Aust Fam Physician 2016:45:31-4

23 Bancej CM, Campbell N, McKay DW, et al. Home blood pressure monitoring among Canadian adults with hypertension: results from the 2009 survey on living with chronic diseases in Canada. Can J Cardiol 2010;26:e152-7.

24 Ostchega Y, Zhang G, Kit BK, et al. Factors associated with home blood pressure monitoring among US adults: National health and nutrition examination survey, 2011-2014. Am J Hypertens 2017;30:1126-32.

25 Wake AD, Bekele DM, Tuji TS. Knowledge and attitude of self-monitoring of blood pressure among adult hypertensive patients on follow-up at selected public hospitals in Arsi zone, Oromia regional state, Ethiopia: a cross-sectional study. Integr Blood Press Control 2020;13:1-13.

26 Paldan K, Sauer H, Wagner N-F. Promoting inequality? self-monitoring applications and the problem of social justice. Al \& society, 2018: 1-11.

27 Paulsen MS, Andersen M, Munck AP, et al. Socio-Economic status influences blood pressure control despite equal access to care. Fam Pract 2012;29:503-10.

28 Seidlerová J, Filipovský J, Wohlfahrt P, et al. Availability and use of home blood pressure measurement in the Czech general population. Cor Vasa 2014;56:e158-63. 